\title{
The ideal retraction property for completely regular semigroups
}

Edmond W.H. Lee

Received: 4 September 2007 / Accepted: 23 June 2008 / Published online: 16 July 2008 (C) Springer Science+Business Media, LLC 2008

This article has been published OnlineFirst, but is withdrawn by the author.

E.W.H. Lee (凶)

Department of Mathematics, Simon Fraser University, Burnaby, British Columbia V5A 1S6, Canada e-mail: ewl@sfu.ca 